\title{
Solitary lymph node metastasis is a distinct subset of colon cancer associated with good survival: a retrospective study of surveillance, epidemiology, and end-results population-based data
}

\author{
Qingguo Li ${ }^{\dagger}$, Yuwei Wang ${ }^{\dagger}$, Guoxiang Cai, Dawei Li and Sanjun Cai
}

\begin{abstract}
Background: Colon cancer with lymph node metastases has been considered as advanced stage and to have poor survival. We postulated that patients with solitary lymph node metastasis are a distinct subset with better colon cancer-specific survival than those with multiple lymph node metastases.

Methods: In this retrospective study, we searched Surveillance, Epidemiology, and End-Results (SEER) population-based data and identified 86,674 patients who had been diagnosed with colon cancer without distant metastases and with less than three metastatic nodes between 1991 and 2005. We divided lymph node status into three subgroups: pNo, pN1a, and pN1b and obtained 5-year colon cancer-specific survival for each pT stage. We used Kaplan-Meier and multivariate Cox regression models to assess correlations between risk factors and survival outcomes.

Results: Analysis of SEER data confirmed that patients with solitary lymph node metastases had better 5-year cancer-specific survival than pN1b according to both univariate and multivariate analysis. This finding was confirmed by further analyses in five PT subgroups. Cancer-specific survival of patients with pT1-2N1a was comparable to that of those with pllA but higher than those with pllB. In addition, survival of patients with pT3-4aN1a was better than those with pllC.
\end{abstract}

Conclusion: Colon cancer patients with solitary lymph node metastasis are a distinct subset with a favorable prognosis; full consideration should be given to this in clinical practice.

Keywords: Colon Cancer, Lymph node metastasis, Surgery, Survival analysis

\section{Background}

Colorectal cancer (CRC), one of the commonest malignancies, is the third leading cause of cancer-related deaths in the United States [1]. The incidence of CRC in Asian countries is increasing rapidly and is likely similar to that in Western countries [2,3]. In China, both the incidence and mortality rate of CRC are increasing [4]. Surgical resection remains the mainstay of treatment of local and regional disease. Lymphadenectomy, a critical component of surgical procedures for patients with $\mathrm{CRC}$, is performed

\footnotetext{
* Correspondence: caisanjun_sh@163.com

${ }^{\dagger}$ Equal contributors

Department of Colorectal Surgery, Fudan University Shanghai Cancer Center,

Department of Oncology, Shanghai Medical College, Fudan University, 270 Dong'an Road, Shanghai 20032, China
}

(c) 2014 Li et al.; licensee BioMed Central Ltd. This is an Open Access article distributed under the terms of the Creative Commons Attribution License (http://creativecommons.org/licenses/by/2.0), which permits unrestricted use, distribution, and reproduction in any medium, provided the original work is properly credited. The Creative Commons Public Domain Dedication waiver (http://creativecommons.org/publicdomain/zero/1.0/) applies to the data made available in this article, unless otherwise stated.

with the aim of achieving complete resection of lesions. In 2000, the National Comprehensive Cancer Network $(\mathrm{NCCN})$ recommended pathologic examination of at least 12 lymph nodes (LNs) in the staging of colon cancer (CC). The number of metastatic LNs has been identified as an independent prognostic factor [5-7]. In the seventh edition of the American Joint Committee on Cancer (AJCC) Cancer Staging Manual for CC, N1 lesions were subdivided into N1a (solitary LN metastasis, SLNM) and N1b (2-3 positive LNs); however, in the current staging system N1a and N1b have been combined. Patients with SLNM might be a distinct subset of those with involved LNs, a subset without the high incidence of systematic disease and poor prognosis of patients with multiple metastases in LNs. In this study, we 
used data from the Surveillance, Epidemiology and EndResults (SEER) registries to analyze the role of SLNM in the long-term survival of patients with $\mathrm{CC}$ and to assess the appropriateness of the N1 classification in the seventh edition of the TNM staging system.

\section{Methods}

The current SEER database consists of 17 population-based cancer registries that represent approximately $28 \%$ of the population of the United States. The SEER data contain no identifiers and are publicly available for studies of cancer-based epidemiology and health policy. The National Cancer Institute's SEER*Stat software (Surveillance Research Program, National Cancer Institute SEER*Stat software, www.seer.cancer.gov/seerstat) was used to identify patients who received a pathologic diagnosis of adenocarcinoma, mucinous adenocarcinoma, or signet-ring carcinoma of the CC (C18.0-19.9) between 1991 and 2005.

Table 1 Characteristics of patients from SEER Database by LN involvement

\begin{tabular}{|c|c|c|c|c|c|}
\hline Characteristic & $\begin{array}{c}\text { Total } \\
(\mathrm{n}=\mathbf{8 6 6 7 4})\end{array}$ & $\begin{array}{c}\text { No } \\
(n=61696)\end{array}$ & $\begin{array}{c}\text { N1a } \\
(n=12416)\end{array}$ & $\begin{array}{c}N 1 b \\
(n=12562)\end{array}$ & $P$ value \\
\hline Media follow up (mo) & 85 & 90 & 78 & 69 & $<0.001$ \\
\hline$(\mathrm{QQR})$ & $(54-121)$ & $(62-124)$ & $(39-116)$ & $(30-108)$ & \\
\hline Years of diagnosis & & & & & 0.102 \\
\hline 1988-1993 & 17214 & 12196 & 2489 & 2529 & \\
\hline 1994-1999 & 24641 & 17436 & 3629 & 3576 & \\
\hline $2000-2003$ & 32064 & 17436 & 6298 & 6457 & \\
\hline Sex & & & & & 0.818 \\
\hline Male & 43210 & 30798 & 6177 & 6235 & \\
\hline Female & 43464 & 30898 & 6239 & 39876327 & \\
\hline Age & & & & & $<0.001$ \\
\hline$<60$ & 27442 & 18170 & 4293 & 4439 & \\
\hline$\geq 60$ & 59232 & 42986 & 8123 & 8123 & \\
\hline Race & & & & & $<0.001$ \\
\hline White & 69850 & 50278 & 9667 & 9905 & \\
\hline Black & 9407 & 6337 & 1574 & 1496 & \\
\hline Other & 7154 & 4872 & 1145 & 1137 & \\
\hline Unknown & 263 & 209 & 30 & 24 & \\
\hline Pathological grading & & & & & $<0.001$ \\
\hline High/moderate & 41097 & 28840 & 6121 & 6136 & \\
\hline Poor/anaplastic & 7723 & 4503 & 1434 & 1786 & \\
\hline Unknown & 1750 & 1232 & 251 & 267 & \\
\hline Histotype & & & & & $<0.001$ \\
\hline Adenocarcinoma & 76387 & 54697 & 10817 & 10873 & \\
\hline Mucinous cell & 9667 & 6671 & 1480 & 1516 & \\
\hline Signet ring cell & 486 & 239 & 96 & 151 & \\
\hline T stage & & & & & $<0.001$ \\
\hline $\mathrm{T} 1$ & 12141 & 11055 & 746 & 340 & \\
\hline $\mathrm{T} 2$ & 14570 & 11995 & 1531 & 1044 & \\
\hline $\mathrm{T} 3$ & 28192 & 18982 & 4532 & 4678 & \\
\hline T4a & 27669 & 17195 & 4860 & 5614 & \\
\hline $\mathrm{T} 4 \mathrm{~b}$ & 4102 & 2469 & 747 & 886 & \\
\hline No. of LNs dissected & & & & & $<0.001$ \\
\hline$<12$ & 47920 & 34671 & 6693 & 6556 & \\
\hline$\geq 12$ & 38754 & 27025 & 5723 & 6006 & \\
\hline
\end{tabular}


Only CC as a single primary tumor was included in current study due to the available information for cause specific survival analysis in SEER database. Patients diagnosed after 2006 were excluded to ensure adequate duration of follow-up. Other exclusion criteria were as follows: incomplete TNM staging, no LNs examined pathologically, more than three LNs with metastases (N2), synchronous distant metastases, patients who had died within 30 days of surgery, and age younger than 18 or older than 80 years.

This study is based on public data from the SEER database: we obtained permission to access the research data files in the SEER program (reference number 12768-Nov2012). Because this study did not involve interaction with human subjects or use personal identifying information, informed consent was not required. The study was approved by the Review Board of Fudan University, Shanghai Cancer Center, Shanghai, China.

\section{Ethics statement}

This study was conducted in compliance with the Helsinki Declaration. Permission to access the research data files in the SEER program was obtained (reference number 12768-Nov2012).

\section{Statistical analysis}

Age, sex, race, extent of primary tumor invasion, total number of LNs examined, number of involved LNs, tumor grade, histological type of tumor, survival time, and cause of death were retrieved from the SEER database. All cases were restaged based on the AJCC-7 guidelines. The primary endpoint of this study, colon cancer cause-specific survival (CCSS), was calculated from the date of diagnosis to the date of cause-specific death. Deaths attributed to the cancer of interest were treated as events and deaths from other causes as censored observations.

$\chi^{2}$ tests were used to test independence, and Student's $t$-test to compare continuous data between the three groups ( $\mathrm{pN} 0, \mathrm{pN} 1 \mathrm{a}$, and $\mathrm{pN} 1 \mathrm{~b}$ ). Exact $95 \%$ confidence intervals (CIs) for proportions were calculated. Survival curves were generated using Kaplan-Meier estimates; differences between the curves were analyzed by the log-

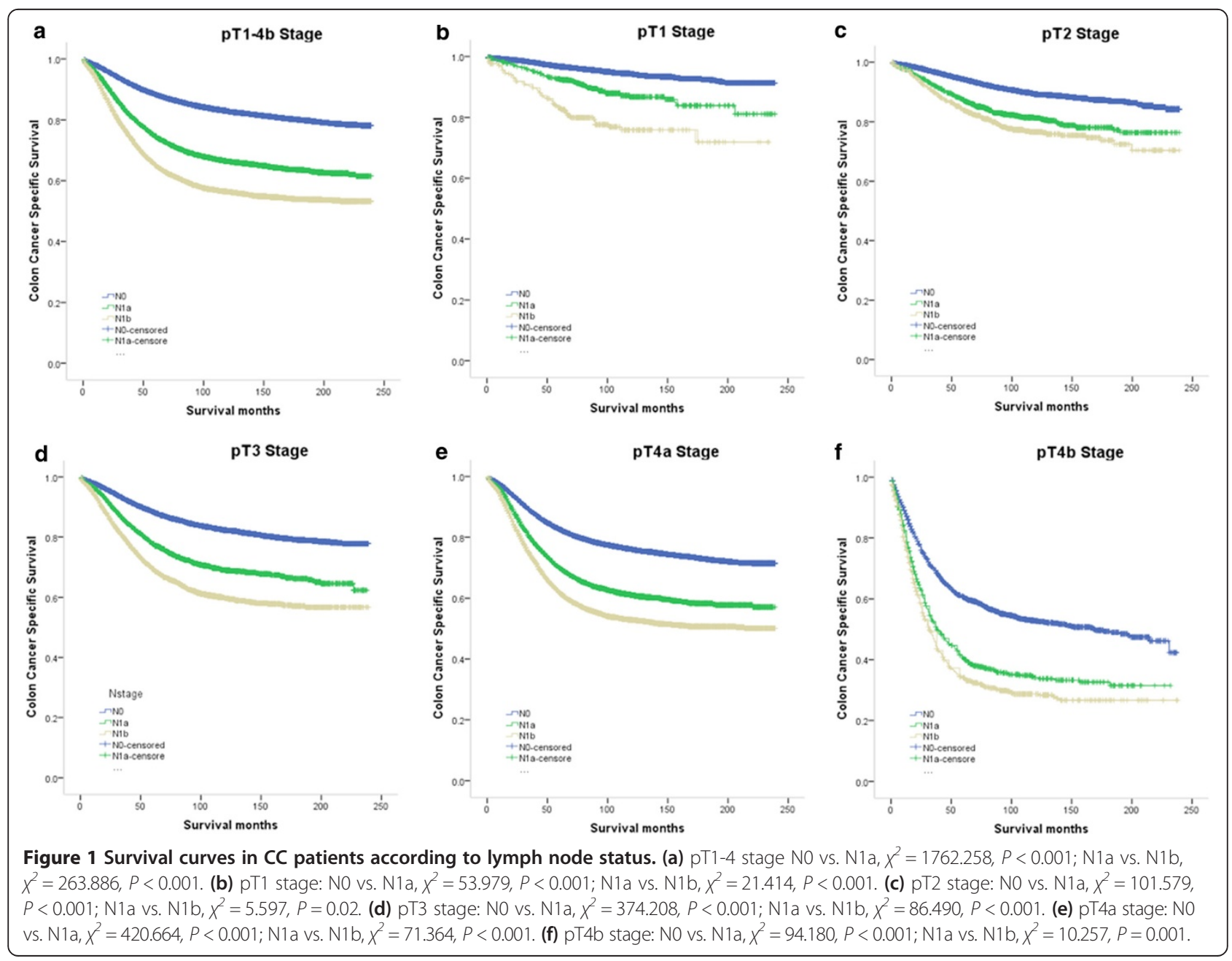


rank test. Multivariate Cox regression models were used to analyze correlations between risk factors and survival outcomes in T1-4 N0-1b patients. All statistical analyses were performed with the statistical software package SPSS for Windows, version 17 (SPSS, Chicago, IL, USA). Statistical significance was set at two-sided $P<0.05$.

\section{Results}

\section{Impact of SLNM on CC survival outcomes}

We identified 86,674 eligible patients over the 15 years covered by the study. These comprised 61,696 patients with no LN metastases, 12,416 with SLNM, and 12,562 with two or three LN metastases. Relevant patient characteristics and pathological features are summarized in Table 1. LN status was correlated with age, race, pathological grading, histological type of tumor, number of LNs dissected, and pT stage.

The median duration of follow-up was 85 months (range 54-121 months) and the overall 5-year CCSS was 83.0\%. The 5-year CCSS of pNO patients, patients with pN1a and patients with pN1b stage was $88.3 \% \pm 0.1 \%$, $74.6 \% \pm 0.4 \%$, and $65.1 \% \pm 0.4 \%$, respectively $(P<0.001)$. There were significant differences in survival between pN0 patients and those with SLNM $(P<0.001)$, between patients with SLNM and with pN1b $(P<0.001)$, and between patients with $\mathrm{pN} 0$ and $\mathrm{pN} 1 \mathrm{~b}(P<0.001)$. We then made a further comparison by $\mathrm{pT}$ stages and found significant differences between all five of them $(P<0.05)$ (Figure 1$)$.

According to univariate and multivariate survival analyses, $\mathrm{pT}$ stage, year of diagnosis, patient age, race, and

Table 2 Univariate and multivariate survival analyses by pN stage in patients with pT1 stage CC

\begin{tabular}{|c|c|c|c|c|c|}
\hline \multirow[b]{2}{*}{ Variable } & \multirow[b]{2}{*}{ 5-year CCS } & \multicolumn{2}{|c|}{ Univariate analysis } & \multicolumn{2}{|c|}{ Multivariate analysis } \\
\hline & & Log rank $x^{2}$ test & $\mathbf{P}$ & HR $(95 \% \mathrm{Cl})$ & $\mathbf{P}$ \\
\hline Years of diagnosis & & 15.944 & $<0.001$ & & $<0.001$ \\
\hline 1988-1993 & $94.9 \%$ & & & Reference & \\
\hline 1994-1999 & $95.6 \%$ & & & $0.815(0.784-0.848)$ & \\
\hline $2000-2003$ & $96.6 \%$ & & & $0.692(0.667-0.718)$ & \\
\hline Sex & & 0.706 & 0.401 & & $\mathrm{NI}$ \\
\hline Male & $96.0 \%$ & & & & \\
\hline Female & $96.2 \%$ & & & & \\
\hline Age & & 45.295 & $<0.001$ & & $<0.001$ \\
\hline$<60$ & $97.6 \%$ & & & Reference & \\
\hline$\geq 60$ & $95.3 \%$ & & & 1.467 (1.419-1.516) & \\
\hline Race & & 16.447 & $<0.001$ & & $<0.001$ \\
\hline White & $96.3 \%$ & & & Reference & \\
\hline Black & $93.4 \%$ & & & $1.428(1.152-1.770)$ & \\
\hline Other ${ }^{a}$ & $97.6 \%$ & & & $0.718(0.528-0.976)$ & \\
\hline Grade & & 19.124 & $<0.001$ & & $<0.001$ \\
\hline High/moderate & $96.2 \%$ & & & Reference & \\
\hline Poor/anaplastic & $93.1 \%$ & & & $1.281(1.234-1.330)$ & \\
\hline Unknown & $96.8 \%$ & & & $0.871(0.802-0.946)$ & \\
\hline Histotype & & 0.923 & 0.337 & & $\mathrm{Nl}$ \\
\hline Adenocarcinoma & $96.1 \%$ & & & & \\
\hline Mucinous/signet ring cell & $96.8 \%$ & & & & \\
\hline No. of LNs dissected & & 0.413 & 0.520 & & $\mathrm{Nl}$ \\
\hline$<12$ & $95.9 \%$ & & & & \\
\hline$\geq 12$ & $96.5 \%$ & & & & \\
\hline LNs status & & 221.646 & $<0.001$ & & $<0.001$ \\
\hline No (pl) & $96.7 \%$ & & & $0.456(0.439-0.473)$ & \\
\hline N1a & $92.6 \%$ & & & Reference & \\
\hline $\mathrm{N} 1 \mathrm{~b}$ & $83.2 \%$ & & & $1.424(1.365-1.486)$ & \\
\hline
\end{tabular}

${ }^{a}$ Other includes American Indian/Alaska native, Asian/Pacific Islander, and unknown. $\mathrm{Nl}$ : not included in multivariate survival analyses. 
LN status were significantly associated with CCSS in all patients. pT2-4a stage female patients had better CCSS than male patients. Tumor grade was an independent factor for CCSS in patients with pT1 and pT3-4b. Except in patients with pT1 stage, the number of LNs dissected was significantly associated with CCSS according to both univariate and multivariate survival analysis. However, histological type of tumor was not a prognostic factor according to both univariate and multivariate survival analyses (Tables 2, 3, 4, 5 and 6).

\section{Comparison of CCSS between patients with pT1-4aN1a} and those with pll stage CC

As presented in Tables 2, 3, 4, 5 and 6, the 5-year CCSS of patients with pIIA, pIIB, and pIIC CC were $88.40 \%$,
$82.70 \%$, and $60.60 \%$, respectively, all being lower than that of those with pT1N1a (92.60\%). The 5-year CCSS of patients with pIIB and pIIC CC was lower than that of those with pT2N1a $(87.20 \%)$ and that of patients with pIIC lower than that of those with pT3N1a (69.90\%). According to AJCC-7 T classification in stage III, we made statistical comparison among pIIA-C, pT1-2N1a, pT1-2N1b, pT34aN1a, pT3-4aN1b, pT4bN1a and pT4bN1b to know whether there were significant differences in CCSS. According to multivariate analysis, the CCSS of patients with pT1-2N1a was similar to that of those with pIIA stage disease (HR, 0.937; 95\% CI, 0.838-1.049; $P=0.259$, using pIIA stage as the reference). Patients with stage pIIB disease had lower 5-year CCSS than those with pT1-2N1a (HR, 0.677; 95\% CI, 0.606-0.757; $P<0.001$, using stage

Table 3 Univariate and multivariate survival analyses by pN stage in patients with pT2 stage CC

\begin{tabular}{|c|c|c|c|c|c|}
\hline \multirow[b]{2}{*}{ Variable } & \multirow[b]{2}{*}{ 5-year CCS } & \multicolumn{2}{|c|}{ Univariate analysis } & \multicolumn{2}{|c|}{ Multivariate analysis } \\
\hline & & Log rank $x^{2}$ test & $P$ & HR $(95 \% \mathrm{Cl})$ & $\mathbf{P}$ \\
\hline Years of diagnosis & & 30.763 & $<0.001$ & & $<0.001$ \\
\hline 1988-1993 & $90.9 \%$ & & & Reference & \\
\hline 1994-1999 & $92.0 \%$ & & & $0.903(0.789-1.033)$ & \\
\hline $2000-2003$ & $93.6 \%$ & & & $0.727(0.637-0.830)$ & \\
\hline Sex & & 27.577 & $<0.001$ & & $<0.001$ \\
\hline Male & $91.8 \%$ & & & Reference & \\
\hline Female & $93.5 \%$ & & & $0.734(0.664-0.812)$ & \\
\hline Age & & 77.274 & $<0.001$ & & $<0.001$ \\
\hline$<60$ & $95.4 \%$ & & & Reference & \\
\hline$\geq 60$ & $91.5 \%$ & & & $1.823(1.612-2.061)$ & \\
\hline Race & & 35.396 & $<0.001$ & & $<0.001$ \\
\hline White & $92.8 \%$ & & & Reference & \\
\hline Black & $89.6 \%$ & & & $1.517(1.306-1.762)$ & \\
\hline Other ${ }^{a}$ & $94.9 \%$ & & & $0.692(0.558-0.858)$ & \\
\hline Grade & & 4.629 & 0.099 & & $\mathrm{NI}$ \\
\hline High/moderate & $92.9 \%$ & & & & \\
\hline Poor/anaplastic & $90.9 \%$ & & & & \\
\hline Unknown & $91.4 \%$ & & & & \\
\hline Histotype & & 0.190 & 0.663 & & $\mathrm{NI}$ \\
\hline Adenocarcinoma & $92.9 \%$ & & & & \\
\hline Mucinous/signet ring cell & $92.5 \%$ & & & & \\
\hline No. of LNs dissected & & 20.732 & $<0.001$ & & $<0.001$ \\
\hline$<12$ & $91.7 \%$ & & & Reference & \\
\hline$\geq 12$ & $94.0 \%$ & & & $0.846(0.761-0.941)$ & \\
\hline LNs status & & 223.132 & $<0.001$ & & 0.002 \\
\hline NO & $94.2 \%$ & & & $0.485(0.423-0.556)$ & \\
\hline $\mathrm{N} 1 \mathrm{a}$ & $87.2 \%$ & & & Reference & \\
\hline $\mathrm{N} 1 \mathrm{~b}$ & $83.8 \%$ & & & $1.270(1.060-1.521)$ & \\
\hline
\end{tabular}

${ }^{2}$ Other includes American Indian/Alaska native, Asian/Pacific Islander, and unknown. $\mathrm{Nl}$ : not included in multivariate survival analyses. 
Table 4 Univariate and multivariate survival analyses by pN stage in patients with pT3 stage CC

\begin{tabular}{|c|c|c|c|c|c|}
\hline \multirow[b]{2}{*}{ Variable } & \multirow[b]{2}{*}{ 5-year CCS } & \multicolumn{2}{|c|}{ Univariate analysis } & \multicolumn{2}{|c|}{ Multivariate analysis } \\
\hline & & Log rank $x^{2}$ test & $\mathbf{P}$ & $\mathrm{HR}(95 \% \mathrm{Cl})$ & $\mathbf{P}$ \\
\hline Years of diagnosis & & 39.995 & $<0.001$ & & $<0.001$ \\
\hline 1988-1993 & $80.3 \%$ & & & Reference & \\
\hline 1994-1999 & $82.6 \%$ & & & $0.874(0.808-0.946)$ & \\
\hline $2000-2003$ & $84.6 \%$ & & & $0.820(0.763-0.881)$ & \\
\hline Sex & & 25.387 & $<0.001$ & & $<0.001$ \\
\hline Male & $82.7 \%$ & & & Reference & \\
\hline Female & $84.3 \%$ & & & $0.855(0.811-0.901)$ & \\
\hline Age & & 169.293 & $<0.001$ & & $<0.001$ \\
\hline$<60$ & $87.3 \%$ & & & Reference & \\
\hline$\geq 60$ & $81.7 \%$ & & & $1.542(1.453-1.638)$ & \\
\hline Race & & 103.809 & $<0.001$ & & $<0.001$ \\
\hline White & $84.1 \%$ & & & Reference & \\
\hline Black & $77.7 \%$ & & & $1.461(1.355-1.574)$ & \\
\hline Other ${ }^{\mathrm{a}}$ & $86.2 \%$ & & & $0.801(0.733-0.896)$ & \\
\hline Grade & & 15.823 & $<0.001$ & & 0.032 \\
\hline High/moderate & $84.0 \%$ & & & Reference & \\
\hline Poor/anaplastic & $80.8 \%$ & & & 1.098 (1.024-1.178) & \\
\hline Unknown & $83.5 \%$ & & & $1.003(0.851-1.182)$ & \\
\hline Histotype & & 1.212 & 0.271 & & $\mathrm{NI}$ \\
\hline Adenocarcinoma & $83.5 \%$ & & & & \\
\hline Mucinous/signet ring cell & $83.8 \%$ & & & & \\
\hline No. of LNs dissected & & 270.983 & $<0.001$ & & $<0.001$ \\
\hline$<12$ & $80.0 \%$ & & & Reference & \\
\hline$\geq 12$ & $86.8 \%$ & & & $0.668(0.633-0.705)$ & \\
\hline LNs status & & 1209.713 & $<0.001$ & & $<0.001$ \\
\hline NO (pllA) & $88.4 \%$ & & & $0.510(0.476-0.546)$ & \\
\hline N1a & $77.8 \%$ & & & Reference & \\
\hline $\mathrm{N} 1 \mathrm{~b}$ & $69.4 \%$ & & & $1.449(1.334-1.561)$ & \\
\hline
\end{tabular}

${ }^{a}$ Other includes American Indian/Alaska native, Asian/Pacific Islander, and unknown.

$\mathrm{Nl}$ : not included in multivariate survival analyses.

pIIB as the reference) but similar 5-year CCSS to those with pT1-2N1b disease (HR, 0.971; 95\% CI, 0.861-1.096; $P=0.634)$. Patients with stage pIIC disease had significantly lower 5-year CCSS than those with pT1-2N1a (HR, 0.254; 95\% CI, 0.224-0.287; $P<0.001$, using stage pIIC as the reference) and those with pT3-4aN1a (HR, 0.601; 95\% CI, 0.560-0.645; $P<0.001$ ), but higher 5-year CCSS than those with pT4bN1a disease (HR, 1.761; 95\% CI, 1.576-1.966; $P<0.001$ ) (Table 7).

\section{Discussion}

LN metastasis is a critical predictor of disease recurrence and CCSS, and therefore an important determinant of postoperative therapy [8]. Various variables, including pathological tumor stage, tumor grade, and degree of differentiation, have been identified as being associated with LN metastases $[9,10]$. In this study, we found that patients' age, race, pathological grading, histological type of tumor, pT stage and number of LNs dissected provided risk stratification for patients with LN metastasis. Tumors with solitary positive node always mean more deep tumors and worsen grading than those with negative LNs, and the seventh edition of the AJCC Cancer Staging Manual for colon classified any pT stage with solitary positive node into pIII or pIV, both which means worsen survival outcomes.

Patients with esophageal cancer and SLNM have been considered a distinct prognostic subgroup with cancer outcomes closer to that of patients with node-negative disease 
Table 5 Univariate and multivariate survival analyses by pN stage in patients with pT4a stage CC

\begin{tabular}{|c|c|c|c|c|c|}
\hline \multirow[b]{2}{*}{ Variable } & \multirow[b]{2}{*}{ 5-year CCS } & \multicolumn{2}{|c|}{ Univariate analysis } & \multicolumn{2}{|c|}{ Multivariate analysis } \\
\hline & & Log rank $x^{2}$ test & $P$ & $\mathrm{HR}(95 \% \mathrm{Cl})$ & $\mathbf{P}$ \\
\hline Years of diagnosis & & 61.405 & $<0.001$ & & $<0.001$ \\
\hline 1988-1993 & $72.8 \%$ & & & Reference & \\
\hline 1994-1999 & $77.1 \%$ & & & $0.836(0.792-0.883)$ & \\
\hline $2000-2003$ & $77.8 \%$ & & & $0.848(0.803-0.896)$ & \\
\hline Sex & & 35.224 & $<0.001$ & & $<0.001$ \\
\hline Male & $75.1 \%$ & & & Reference & \\
\hline Female & $77.2 \%$ & & & $0.859(0.822-0.898)$ & \\
\hline Age & & 136.610 & $<0.001$ & & $<0.001$ \\
\hline$<60$ & $79.9 \%$ & & & Reference & \\
\hline$\geq 60$ & $74.5 \%$ & & & $1.383(1.316-1.454)$ & \\
\hline Race & & 85.397 & $<0.001$ & & $<0.001$ \\
\hline White & $76.7 \%$ & & & Reference & \\
\hline Black & $69.1 \%$ & & & $1.357(1.270-1.450)$ & \\
\hline Other ${ }^{\mathrm{a}}$ & $79.7 \%$ & & & $0.845(0.777-0.918)$ & \\
\hline Grade & & 52.978 & $<0.001$ & & 0.032 \\
\hline High/moderate & $77.3 \%$ & & & Reference & \\
\hline Poor/anaplastic & $71.5 \%$ & & & $1.178(1.116-1.244)$ & \\
\hline Unknown & $75.5 \%$ & & & $1.053(0.917-1.210)$ & \\
\hline Histotype & & 0.011 & 0.915 & & $\mathrm{Nl}$ \\
\hline Adenocarcinoma & $76.2 \%$ & & & & \\
\hline Mucinous/signet ring cell & $76.0 \%$ & & & & \\
\hline No. of LNs dissected & & 266.370 & $<0.001$ & & $<0.001$ \\
\hline$<12$ & $72.4 \%$ & & & Reference & \\
\hline$\geq 12$ & $80.4 \%$ & & & $0.708(0.676-0.740)$ & \\
\hline LNs status & & 1213.378 & $<0.001$ & & $<0.001$ \\
\hline NO (p\|B) & $82.7 \%$ & & & $0.559(0.528-0.592)$ & \\
\hline N1a & $69.9 \%$ & & & Reference & \\
\hline $\mathrm{N} 1 \mathrm{~b}$ & $61.7 \%$ & & & $1.317(1.239-1.401)$ & \\
\hline
\end{tabular}

${ }^{\mathrm{a}}$ Other includes American Indian/Alaska native, Asian/Pacific Islander, and unknown.

$\mathrm{Nl}$ : not included in multivariate survival analyses.

and better than any other node-positive subgroup [11]. It has even been suggested that there is no survival difference between patients with SLNM and those with N0 esophageal squamous cell carcinoma; that is, SLNM does not affect the prognosis [12]. Bardia et al. [13] reported that six rectal adenocarcinoma patients with a solitary inguinal LN metastasis survived a mean of 42 months from diagnosis, three of the six patients still being alive after a mean duration of 40 months of follow-up when the article was accepted for publication. It is important to investigate the prognosis of patients with SLNM; the presence of multiple LN metastases is already known to be associated with systematic disease and poor prognosis [14]. However, thus far no studies have investigated the prognosis of CC patients with SLNM.
In this study we analyzed the SEER data of 86,674 CC patients and found significant differences in survival between patients with SLNM and those with pN1b disease, verifying our hypothesis that SLNM is the earliest form of LN invasion and has heterogeneous outcomes. Soni et al. confirmed the sentinel node as the only site of metastasis in $41 \%$ of node-positive patients [10] and considered that the patients with SLNM did not have systemic disease. We further investigated survival differences by $\mathrm{T}$ stage category and found that patients with SLNM in all five pT stages had a significantly longer 5-year CCSS than did pN1b patients, indicating that CC with a SLNM may have an inherently favorable biologic character.

Of interest is that, in our study, the 5-year CCSS of patients with pT1N1a CC was $92.6 \%$, which is higher than 
Table 6 Univariate and multivariate survival analyses by pN stage in patients with pT4b stage CC

\begin{tabular}{|c|c|c|c|c|c|}
\hline \multirow[b]{2}{*}{ Variable } & \multirow[b]{2}{*}{ 5-year CCS } & \multicolumn{2}{|c|}{ Univariate analysis } & \multicolumn{2}{|c|}{ Multivariate analysis } \\
\hline & & Log rank $x^{2}$ test & $P$ & HR (95\% Cl) & $P$ \\
\hline Years of diagnosis & & 37.575 & $<0.001$ & & 0.001 \\
\hline 1988-1993 & $44.4 \%$ & & & Reference & \\
\hline 1994-1999 & $49.2 \%$ & & & $0.905(0.807-1.014)$ & \\
\hline $2000-2003$ & $55.7 \%$ & & & $0.809(0.726-0.902)$ & \\
\hline Sex & & 1.163 & 0.281 & & $\mathrm{NI}$ \\
\hline Male & $51.9 \%$ & & & & \\
\hline Female & $50.7 \%$ & & & & \\
\hline Age & & 41.821 & $<0.001$ & & $<0.001$ \\
\hline$<60$ & $56.7 \%$ & & & Reference & \\
\hline$\geq 60$ & $48.0 \%$ & & & $1.329(1.213-1.456)$ & \\
\hline Race & & 19.460 & $<0.001$ & & $<0.001$ \\
\hline White & $52.0 \%$ & & & Reference & \\
\hline Black & $42.3 \%$ & & & 1.337 (1.175-1.522) & \\
\hline Other $^{a}$ & $56.4 \%$ & & & $0.920(0.781-1.084)$ & \\
\hline Grade & & 48.208 & $<0.001$ & & $<0.001$ \\
\hline High/moderate & $54.3 \%$ & & & Reference & \\
\hline Poor/anaplastic & $44.8 \%$ & & & $1.343(1.219-1.479)$ & \\
\hline Unknown & $41.7 \%$ & & & $1.324(1.094-1.601)$ & \\
\hline Histotype & & 0.024 & 0.877 & & $\mathrm{NI}$ \\
\hline Adenocarcinoma & $51.2 \%$ & & & & \\
\hline Mucinous/signet ring cell & $51.4 \%$ & & & & \\
\hline No. of LNs dissected & & 158.496 & $<0.001$ & & $<0.001$ \\
\hline$<12$ & $42.4 \%$ & & & Reference & \\
\hline$\geq 12$ & $60.4 \%$ & & & $0.598(0.548-0.653)$ & \\
\hline LNs status & & 1213.378 & $<0.001$ & & $<0.001$ \\
\hline No (p\|C) & $60.6 \%$ & & & $0.596(0.534-0.666)$ & \\
\hline $\mathrm{N} 1 \mathrm{a}$ & $40.5 \%$ & & & Reference & \\
\hline $\mathrm{N} 1 \mathrm{~b}$ & $34.1 \%$ & & & $1.201(1.062-1.358)$ & \\
\hline
\end{tabular}

${ }^{\mathrm{a}}$ Other includes American Indian/Alaska native, Asian/Pacific Islander, and unknown.

$\mathrm{Nl}$ : not included in multivariate survival analyses.

that of those with pIIA (88.4\%). The 5-year CCSS of patients with pT1-2N1a stage was similar to that of those with stage pIIA, but significantly greater than that of those with pIIB disease. Patients with pT3-4N1a disease had a better 5-year CCSS than those with pIIC. What could explain why patients with SLNM have a better CCSS than those with no LN metastases? We postulate that the major reasons are incomplete surgical resection and/or inadequate node sampling, resulting in inaccurate TNM staging. In the United States, more than $60 \%$ of colon cancer is under-staged after surgery [15]. At least 12 examined LNs is the benchmark for accurately ascertaining pathological node stage. Numerous observational studies of the impact of the number of LNs retrieved in patients with $\mathrm{CC}$ have shown a clear survival benefit with increasing numbers of LNs examined, especially in stage II patients [16-18]; our findings are consistent with these data. The more nodes that are examined and found negative, the more likely that a stage II patient is really node-negative, whereas lower nodal counts increase the risk that a node-positive patient will be misclassified as node-negative. When the technique of sentinel lymph node mapping is used, there is a $15 \%$ absolute increase in nodal positivity [10]. Such understaging leads to under-treatment: many under-staged patients do not receive the adjuvant chemotherapy that is essential for survival benefit. About $15 \%$ to $20 \%$ of stage I/II colon patients develop recurrence within 5 years of diagnosis [19]. The benefits of increased nodal counts in nodepositive patients remain controversial. Because we used the number of LNs dissected as a co-variable in our univariate 
Table 7 Comparison of 5-year CCSS of patients with SLNM and pll stage CC

\begin{tabular}{|c|c|c|c|c|c|c|}
\hline Variable & HR $(95 \% \mathrm{Cl})$ & $\mathbf{P}$ & HR $(95 \% \mathrm{Cl})$ & $\mathbf{P}$ & HR (95\% Cl) & \\
\hline pTNM stage & & $<0.001$ & & $<0.001$ & & $<0.001$ \\
\hline$\| \mathrm{A}$ & Reference & & $0.723(0.688-0.759)$ & $<0.001$ & $0.271(0.252-0.290)$ & $<0.001$ \\
\hline$\| \mathrm{B}$ & 1.384 (1.317-1.453) & $<0.001$ & Reference & & $0.374(0.350-0.401)$ & $<0.001$ \\
\hline$\| C$ & $3.695(3.443-3.966)$ & $<0.001$ & $2.671(2.495-2.859)$ & $<0.001$ & Reference & \\
\hline $\mathrm{T} 1-2 \mathrm{~N} 1 \mathrm{a}$ & $0.937(0.838-1.049)$ & 0.259 & $0.677(0.606-0.757)$ & $<0.001$ & $0.254(0.224-0.287)$ & $<0.001$ \\
\hline T3-4aN1a & $2.221(2.109-2.339)$ & $<0.001$ & 1.605 (1.529-1.685) & $<0.001$ & $0.601(0.560-0.645)$ & $<0.001$ \\
\hline T4bN1a & 6.506 (5.886-7.192) & $<0.001$ & $4.703(4.262-5.189)$ & $<0.001$ & $1.761(1.576-1.966)$ & $<0.001$ \\
\hline $\mathrm{T} 1-2 \mathrm{~N} 1 \mathrm{~b}$ & 1.344 (1.189-1.518) & $<0.001$ & $0.971(0.861-1.096)$ & 0.634 & $0.364(0.319-0.414)$ & $<0.001$ \\
\hline T3-4aN1b & $3.060(2.915-3.211)$ & $<0.001$ & $2.212(2.115-2.312)$ & $<0.001$ & $0.828(0.774-0.886)$ & $<0.001$ \\
\hline T4bN1b & $8.011(7.328-8.757)$ & $<0.001$ & $5.790(5.307-6.317)$ & $<0.001$ & 2.168 (1.961-2.397) & $<0.001$ \\
\hline
\end{tabular}

$P$ values refer to comparison between each group and the reference group and were adjusted for year of diagnosis, age, sex, pathological grading, histological type of tumor, and number of LNs dissected as covariates.

and multivariate survival analyses, our findings suggest that SLNM CC has inherently favorable biologic behavior.

Despite this, patients with positive LNs are routinely referred for adjuvant therapy [20]. NCCN guidelines (version I.2014) recommend adjuvant chemotherapy for stage pIII $\mathrm{CC}$ patients, including those with stage pT1-2N1a, but do not recommend adjuvant chemotherapy for stage pII patients who are assessed as low risk. Many physicians assume that pII stage patients have a better CCSS than pIII patients. Also patients with pII stage are less willing to undergo chemotherapy than pIII stage patients in clinical practice $[21,22]$. Thus, stage pT1-2N1a CC patients may be overtreated and stage pII patients under-treated. Unfortunately, because information about chemotherapy is not available in the SEER database, we were not able to analyze this issue further. Postoperative adjuvant treatment with fluorouracil and levamisole reportedly reduces the mortality rate by more than $30 \%$ in patients with stage III CC [23-25]. However, with CCSS as high as $92.6 \%$ in patients with pT1N1a stage disease, does adjuvant chemotherapy benefit all patients in this subgroup? AJCC staging was initiated to assess survival and guide clinical practice; we believe it should emphasize the distinctive characteristics of patients with SLNM.

Although this is a large population-based study evaluating the subgroup of CC patients with SLNM, it has several potential limitations. First, the SEER database lacks data concerning several important tumor characteristics (e.g., perineural and lymphovascular invasion), chemotherapy (neoadjuvant and adjuvant), and patient outcome (recurrence and metastasis). Thus, our analyses could not adjust for these potential confounding factors. Second, there may be minor misclassification of pT4 stage. In the first years of this century, the AJCC defined pT4a as CCs infiltrating adjacent organs or structures without perforation of visceral peritoneum and $\mathrm{pT} 4 \mathrm{~b}$ as those perforating the visceral peritoneum [26]. However, in the 7th AJCC edition, a CC is classified as pT4a when it infiltrates the serosa and as pT4b when it infiltrates adjacent organs: this may influence the classification of pT4a and T4b CCSS. Third, because SEER data provide no information about the distribution of SLNM, we could not tell whether a SLNM was a skip metastasis and therefore could not ascertain whether there is a difference in survival between skip and no skip groups.

\section{Conclusion}

In conclusion, our study shows that patients with SLNM have a better 5 -year CCSS than patients with $\mathrm{pN} 1 \mathrm{~b}$ disease. Patients with pT1-2N1a stage and those with p IIA have a similar 5-year CCSS. Patients with pT3-4aN1a stage have a higher 5-year CCSS rate than those with pIIC disease. The overwhelming advantage in long-term survival of CC patients with SLNM over those with pN1b stage warrants careful attention in clinical practice and TNM stage revision.

\section{Abbreviations}

AJCC: American Joint Committee on Cancer; CCSS: colorectal cancer cause-specific survival rate; CRC: colorectal cancer; CC: colon cancer; LN: lymph node; NCCN: National Comprehensive Cancer Network; SEER: National Cancer Institute's Surveillance, Epidemiology, and End Results; SLNM: solitary lymph node metastasis.

\section{Competing interests}

The authors declare that they have no competing interests.

\section{Authors' contributions}

QGL and SJC designed the study. YWW and DWL provided the databases. QGL, YWW, GXC and SJC assembled and analyzed the data. QGL, GXC and YWW wrote the manuscript. All authors read and approved the final manuscript.

\section{Acknowledgments}

This study used the linked SEER database. The interpretation and reporting of these data are the sole responsibility of the authors. The authors acknowledge the efforts of the Surveillance, Epidemiology, and End-Results (SEER) Program tumor registries in the creation of the SEER database.

\section{Funding}

This study was supported by grants from the National Natural Science Foundation of China (No. 81001055; 81101586), Shanghai Pujiang Program (No. 13PJD008), National High Technology Research and Development Program (863 Program, No. 2012AA02A506) and Shanghai Shenkang Program (No. SHDC12012120). 
Received: 15 January 2014 Accepted: 20 May 2014

Published: 24 May 2014

\section{References}

1. Siegel R, Naishadham D, Jemal A: Cancer statistics, 2013. CA Cancer J Clin 2013, 63(1):11-30.

2. Sung JJ, Lau JY, Young GP, Sano Y, Chiu HM, Byeon JS, Yeoh KG, Goh KL, Sollano J, Rerknimitr R, Matsuda T, Wu KC, Ng S, Leung SY, Makharia G, Chong VH, Ho KY, Brooks D, Lieberman DA, Chan FK, Asia Pacific Working Group on Colorectal Cancer: Asia Pacific consensus recommendations for colorectal cancer screening. Gut 2008, 57(8):1166-1176.

3. Byeon JS, Yang SK, Kim TI, Kim WH, Lau JY, Leung WK, Fujita R, Makharia GK, Abdullah M, Hilmi I, Sollano J, Yeoh KG, Wu DC, Chen MH, Kongkam P, Sung $J$ J, Asia Pacific Working Group for Colorectal Cancer: Colorectal neoplasm in asymptomatic Asians: a prospective multinational multicenter colonoscopy survey. Gastrointest Endosc 2007, 65(7):1015-1022.

4. Lei T, Chen WQ, Zhang SW, Lei TH, Ying Q, He ZY, Wang XH: Prevalence trend of colorectal cancer in 10 cities and counties in China from 1988 to 2002. Zhonghua Zhong Liu Za Zhi 2009, 31(6):428-433.

5. Gunderson LL, Jessup JM, Sargent DJ, Greene FL, Stewart AK: Revised TN categorization for colon cancer based on national survival outcomes data. J Clin Oncol 2010, 28(2):264-271.

6. Hong KD, Lee SI, Moon HY: Lymph node ratio as determined by the 7th edition of the American Joint Committee on Cancer staging system predicts survival in stage III colon cancer. J Surg Oncol 2011, 103(5):406-410.

7. Suzuki O, Sekishita Y, Shiono T, Ono K, Fujimori M, Kondo S: Number of lymph node metastases is better predictor of prognosis than level of lymph node metastasis in patients with node-positive colon cancer. J Am Coll Surg 2006, 202(5):732-736.

8. Shariat SF, Ehdaie B, Rink M, Cha EK, Svatek RS, Chromecki TF, Fajkovic H, Novara G, David SG, Daneshmand S, Fradet Y, Lotan Y, Sagalowsky Al, Clozel T, Bastian PJ, Kassouf W, Fritsche HM, Burger M, Izawa Jl, Tilki D, Abdollah F, Chun FK, Sonpavde G, Karakiewicz PI, Scherr DS, Gonen M: Clinical nodal staging scores for bladder cancer: a proposal for preoperative risk assessment. Eur Urol 2012, 61(2):237-242.

9. Tu SL, Ye ZY, Deng GL, Zhao ZS, Dong QJ, Zheng BA, Ding LP, Cao HF: Rule of lymph node metastasis in colorectal cancer and its affecting factors. Zhonghua Wei Chang Wai Ke Za Zhi 2007, 10(3):257-260.

10. Soni M, Wiese D, Korant A, Sirop S, Chakravarty B, Gayar A, Bilchik A, Beutler T, Ratz D, Saha S: Comparison of nodal positivity between SLNM vs conventional surgery in colon cancer patients with $<12$ and $>/=12$ lymph nodes harvested. Am J Surg 2011, 202(2):207-213.

11. O'Riordan JM, Rowley S, Murphy JO, Ravi N, Byrne PJ, Reynolds JV: Impact of solitary involved lymph node on outcome in localized cancer of the esophagus and esophagogastric junction. J Gastrointest Surg 2007, 11(4):493-499.

12. Kunisaki C, Makino H, Kimura J, Oshima T, Fujii S, Takagawa R, Kosaka T, Ono $H$, Akiyama $H$, Endo I: Therapeutic strategy for esophageal cancer based on solitary lymph node metastasis. Hepatogastroenterol 2011, 58(110-111):1561-1565.

13. Bardia A, Greeno E, Miller R, Alberts S, Dozois E, Haddock M, Limburg P: Is a solitary inguinal lymph node metastasis from adenocarcinoma of the rectum really a metastasis? Colorectal Dis 2010, 12(4):312-315.

14. Peyre CG, Hagen JA, DeMeester SR, Van Lanschot JJ, Hölscher A, Law S, Ruol A, Ancona E, Griffin SM, Altorki NK, Rice TW, Wong J, Lerut T, DeMeester TR: Predicting systemic disease in patients with esophageal cancer after esophagectomy: a multinational study on the significance of the number of involved lymph nodes. Ann Surg 2008, 248(6):979-985.

15. Bilimoria KY, Bentrem DJ, Stewart AK, Talamonti MS, Winchester DP, Russell TR, Ko CY: Lymph node evaluation as a colon cancer quality measure: a national hospital report card. J Nat/ Cancer Inst 2008, 100(18):1310-1317.

16. Vather R, Sammour T, Kahokehr A, Connolly AB, Hill AG: Lymph node evaluation and long-term survival in stage II and stage III colon cancer: a national study. Ann Surg Oncol 2009, 16(3):585-593.

17. Le Voyer TE, Sigurdson ER, Hanlon AL, Mayer RJ, Macdonald JS, Catalano PJ, Haller DG: Colon cancer survival is associated with increasing number of lymph nodes analyzed: a secondary survey of intergroup trial INT-0089. J Clin Oncol 2003, 21(15):2912-2919.

18. Prandi M, Lionetto R, Bini A, Francioni G, Accarpio G, Anfossi A, Ballario E, Becchi G, Bonilauri S, Carobbi A, Cavaliere P, Garcea D, Giuliani L, Morziani E, Mosca F, Mussa A, Pasqualini M, Poddie D, Tonetti F, Zardo L, Rosso R:
Prognostic evaluation of stage B colon cancer patients is improved by an adequate lymphadenectomy: results of a secondary analysis of a large scale adjuvant trial. Ann Surg 2002, 235(4):458-463.

19. Saha S, Sehgal R, Patel M, Doan K, Dan A, Bilchik A, Beutler T, Wiese D, Bassily $N$, Yee C: A multicenter trial of sentinel lymph node mapping in colorectal cancer: prognostic implications for nodal staging and recurrence. Am J Surg 2006, 191(3):305-310.

20. Chau I, Cunningham D: Adjuvant therapy in colon cancer: current status and future directions. Cancer Treat Rev 2002, 28(5):223-236.

21. O'Connell JB, Maggard MA, Ko CY: Colon cancer survival rates with the new American Joint Committee on Cancer sixth edition staging. J Natl Cancer Inst 2004, 96(19):1420-1425.

22. Rottoli M, Stocchi L, Dietz DW: T4NO colon cancer has oncologic outcomes comparable to stage III in a specialized center. Ann Surg Oncol 2012, 19(8):2500-2505.

23. Moertel CG, Fleming TR, Macdonald JS, Haller DG, Laurie JA, Goodman PJ, Ungerleider JS, Emerson WA, Tormey DC, Glick JH, Veeder MH, Mailliard JA: Levamisole and fluorouracil for adjuvant therapy of resected colon carcinoma. N Engl J Med 1990, 322(6):352-358.

24. Gill S, Loprinzi CL, Sargent DJ, Thome SD, Alberts SR, Haller DG, Benedetti J, Francini G, Shepherd LE, Francois Seitz J, Labianca R, Chen W, Cha SS, Heldebrant MP, Goldberg RM: Pooled analysis of fluorouracil-based adjuvant therapy for stage II and III colon cancer: who benefits and by how much? J Clin Oncol 2004, 22(10):1797-1806.

25. Taal BG, Van Tinteren H, Zoetmulder FA: Adjuvant 5FU plus levamisole in colonic or rectal cancer: improved survival in stage II and III. Br J Cancer 2001, 85(10):1437-1443.

26. Garcia-Granero E, Frasson M, Pous S, Cervantes A: T4a and t4b colorectal cancer: what does this mean nowadays? Dis Colon Rectum 2012, 55(11):e367.

doi:10.1186/1471-2407-14-368

Cite this article as: Li et al:: Solitary lymph node metastasis is a distinct subset of colon cancer associated with good survival: a retrospective study of surveillance, epidemiology, and end-results population-based data. BMC Cancer 2014 14:368.

\section{Submit your next manuscript to BioMed Central and take full advantage of:}

- Convenient online submission

- Thorough peer review

- No space constraints or color figure charges

- Immediate publication on acceptance

- Inclusion in PubMed, CAS, Scopus and Google Scholar

- Research which is freely available for redistribution

Submit your manuscript at www.biomedcentral.com/submit
C) Biomed Central 